\title{
Proteomic changes across a natural temperature gradient in a marine gastropod
}

\author{
M. Christina Vasquez ${ }^{\mathrm{a}, *, 1}$, Marilla R. Lippert ${ }^{\mathrm{a}}$, Crow White ${ }^{\mathrm{a}}$, Ryan K. Walter ${ }^{\mathrm{b}}$, Lars Tomanek ${ }^{\mathrm{a}}$ \\ a Biological Sciences Department, California Polytechnic State University, San Luis Obispo, CA, 93407, USA \\ ${ }^{\mathrm{b}}$ Physics Department, California Polytechnic State University, San Luis Obispo, CA, 93407, USA
}

\section{A R T I C L E I N F O}

\section{Keywords:}

Thermal stress

Protein abundance

Gastropod

Kelletia kelletii

Fisheries

California channel islands

\begin{abstract}
A B S T R A C T
Responses of marine ectotherms to variable environmental temperature often entails maintanence of cellular homeostasis and physiological function through temperature compensation and physiological changes. We investigated the physiological response to thermal stress by examining proteomic changes in the marine kelp forest gastropod and emerging fisheries species Kellet's whelk (Kelletia kelletii) across a naturally-existing thermal gradient that ranges from a warmer-water site inside the species' native range and extends to the northern, coldwater edge of the range. We hypothesized that abundance of cellular stress response and energy metabolism proteins would increase with decreasing temperature in support of cold-compensation. Our exploratory proteomic analysis of whelk gill tissue ( $N=6$ whelks) from each of the four California Channel Island sites revealed protein abundance changes related to the cytoskeleton, energy metabolism/oxidative stress, and cell signaling. The changes did not correlate consistently with temperature. Nonetheless, whelks from the coldest island site showed increased abundance of energy metabolism and oxidative stress proteins, possibly suggesting oxidative damage of lipid membranes that is ameliorated by antioxidants and may aid in their cold stress response. Similarly, our exploratory analysis revealed abundances of cell signaling proteins that were higher at the coldest site compared to the warmest site, possibly indicating an importance for cell signaling regulation in relatively cooler environments. This study provides protein targets for future studies related to thermal effects in marine animals and may contribute to understanding the physiological response of marine organisms to future ocean conditions.
\end{abstract}

\section{Introduction}

To maintain cellular homeostasis and physiological function, ectotherms respond to a change in environmental temperature with temperature compensation, mainly through metabolic acclimation, by maintaining physiological rates when thermal conditions are outside of the organism's preferred body temperature (Pörtner et al., 2006; Somero, 2010). In general, responses include changes in enzyme concentration and switching to synthesis of protein isoforms that function best at a specific thermal optimum (Somero et al., 2017). Temperature compensation can result in physiological costs since processes like de novo synthesis of proteins, such as those induced under cold stress (lipid desaturases), or heat stress (heat shock proteins) require ATP (Feder and Hofmann, 1999; Thieringer et al., 1998). In particular, cold adaptation can alter membrane lipid profiles (e.g., elevated proportion of polyunsaturated fatty acids) to maintain plasma membrane fluidity, a response that can increase the risk of cellular oxidative damage by reactive oxygen species (ROS) (Abele and Puntarulo, 2004; Hazel, 1995). Also, cold compensation can induce proliferation of mitochondria and their enzymes to maintain energy supply (Pörtner et al., 2000), and cold stress can increase the strength of base pair bonds in nucleic acids making the structure too stable (Hochachka and Somero, 2002; Somero et al., 2017). Therefore, a shift in cold-stress tolerance due to acclimation requires physiological processes that are energetically costly and thus reduce the portion of the overall energy budget that can be invested into growth, maintenance, and reproduction (Sokolova, 2013; Sokolova et al., 2012).

Our study uses a naturally-existing thermal gradient that ranges from a warmer-water site inside a marine species' native, historic range and extends to the northern, cold-water edge of the historic range to investigate proteomic changes associated with changing thermal exposure. We focused on the marine gastropod Kellet's whelk (Kelletia

\footnotetext{
* Corresponding author. Biology Department, Loyola Marymount University, 1 LMU Drive, Los Angeles, CA, 90045, USA.

E-mail address: maria.vasquez@lmu.edu (M.C. Vasquez).

${ }^{1}$ Present Address: Biology Department, Loyola Marymount University, Los Angeles CA 90045 USA.
} 


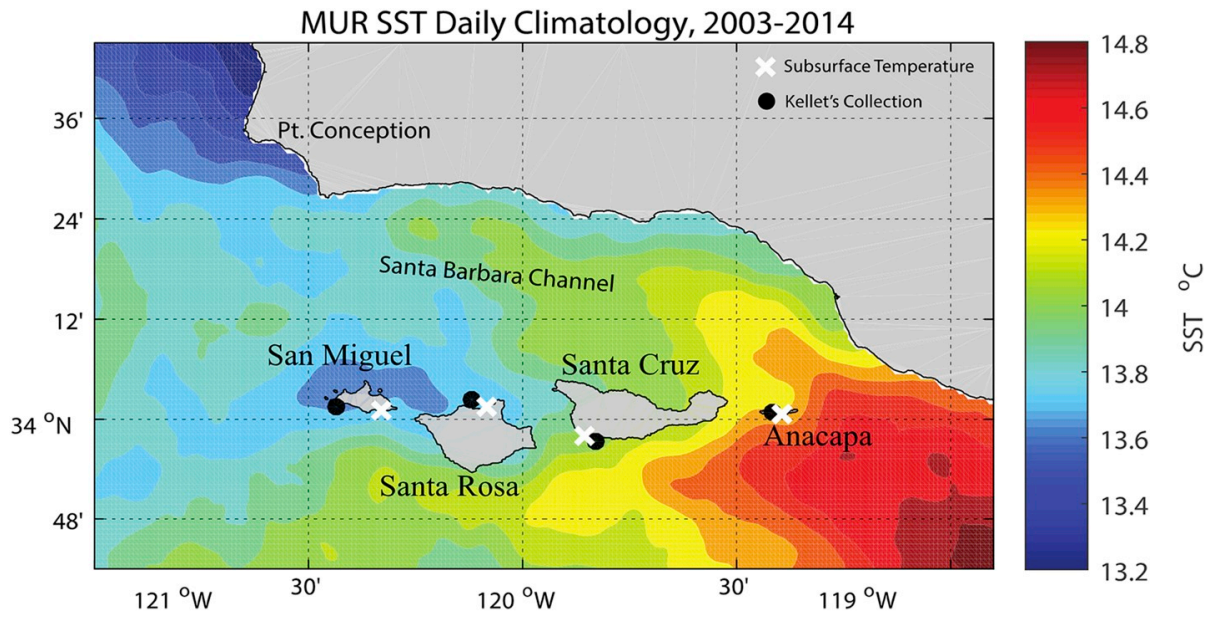

Fig. 1. Multiscale Ultrahigh Resolution (MUR) daily climatology sea surface temperature $\left(\mathrm{SST},{ }^{\circ} \mathrm{C}\right)$ of the Santa Barbara Channel region highlighting the persistent temperature gradient across the northernmost Channel Islands (San Miguel, Santa Rosa, Santa Cruz, and Anacapa). The daily climatology represents the mean of all daily MUR SST data from 2003 to 2014. Also shown are the Kellet's whelk collection sites (black dots) and location of subsurface temperature measurements (white $\mathrm{x}$ ) at each island. kelletii), an ecologically significant predator in kelp forest ecosystems (Halpern et al., 2006), and an emerging fisheries species in California (Aseltine-Neilson et al., 2006), characterized by sessile adult and dispersive larval stages. Within its native, historic range, Kellet's whelk populations are spread across a chain of four islands (The Channel Islands: Anacapa, Santa Cruz, Santa Rosa, San Miguel; Kushner et al., 2013).

Although relatively proximate to one another, each island in the group exhibits a different thermal regime, and we utilized this naturally occurring thermal gradient for our experimental design. At one end of the chain of islands, our study site at Anacapa Island exhibits temperatures typical of the central region of Kellet's whelk's range, while, at the other end of the chain, our study site at San Miguel Island is located closer to the edge of the species' range and exhibits a cooler temperature environment, with Santa Cruz and Santa Rosa Islands located between the two geographically and in temperature (Zacherl et al., 2003). The entire study is limited to within a relatively small geographic domain (about $90 \mathrm{~km}$ between sites) with high gene flow among the sites (via the larval stage; White et al., 2010), enabling us to minimize effects of confounding genetic differences and kelp forest ecological community differences among the sites, and focus on providing an initial assessment of the possible effects of temperature differences on physiological acclimation.

We coupled our proteomic analysis with subsurface temperature data collected at the Channel Islands and near each of our Kellet's whelk collection sites to provide a preliminary analysis of possible associated changes in protein abundance by the whelks with changes in ocean temperatures observed at the island sites. Proteins act as the biochemical machinery functioning in an organism's response to changing environments (i.e., the molecular phenotype) and allow for studying the potential for acclimation to stressful conditions (Tomanek, 2014). Proteomics also allows for the investigation of cellular signaling events that connect external stimuli to biochemical responses (Tomanek, 2014). Thus, we hypothesized that there would be a linear relationship between changes in protein abundance and island site (a proxy for thermal habitat). In particular, we hypothesized that whelks found at sites with colder temperatures would increase their abundance of cellular stress response proteins involved in proteostasis (molecular chaperones, proteolysis), antioxidants, and energy metabolism.

This study represents the first exploration of the proteome of $K$. kelletii in relation to environmental conditions. Furthermore, while numerous studies have investigated temperature effects on proteomic changes by organisms in controlled laboratory settings (Dowd, 2012), our analysis of individuals sampled in situ in their natural environment provides insight on how temperature affects protein expression levels in a species' natural environment. A review of 31 studies focused on environmental proteomics found that only one study analyzed samples from field-collected animals (Dowd, 2012). Thus, our field-based results provide novel information about proteomic changes that are influenced by natural thermal variability, which is unavailable in a lab study and may help to guide future lab-based proteomic studies. Finally, our results may contribute to understanding the physiological response of marine organisms to changing ocean conditions, particularly changing thermal environments.

\section{Materials and methods}

\subsection{Study species}

Kellet's whelk is a slow-growing, dioecious species with sedentary, demersal adults and a pelagic larval phase. Whelks reach sexual maturity at $\sim 60 \mathrm{~mm}$ shell length at $\sim 5$ year's age (exact age uncertain) (Rosenthal, 1970; White et al., 2010). Reproduction occurs annually in late spring and in the summer. Mature female Kellet's whelks deposit egg capsules on hard substrates, where eggs develop for $\sim 32$ days before hatching as pelagic larvae that disperse for $\sim 5.5-9$ weeks (Romero et al., 2012). Kellet's whelks feed on mobile and sessile invertebrates (Rosenthal, 1971), and occupy depths of 2-70 m on rocky reefs and in kelp forests (Rosenthal, 1970).

\subsection{Collection site}

Kellet's whelks ( $N=6$ individuals per site) were collected at four subtidal reef sites at the California Northern Channel Islands, Anacapa (Anacapa North, $44^{\circ} 38^{\prime} 25^{\prime \prime} \mathrm{N}, 124^{\circ} 03^{\prime} 10^{\prime \prime} \mathrm{W}$ ), Santa Cruz (Gull Island, $44^{\circ} 38^{\prime} 25^{\prime \prime} \mathrm{N}, 124^{\circ} 03^{\prime} 10^{\prime \prime} \mathrm{W}$ ), Santa Rosa (Rhodes Reef, $44^{\circ} 38^{\prime} 25^{\prime \prime} \mathrm{N}$, $124^{\circ} 03^{\prime} 10^{\prime \prime} \mathrm{W}$ ), and San Miguel (Adam's Cove, $44^{\circ} 38^{\prime} 25^{\prime \prime} \mathrm{N}$, $124^{\circ} 03^{\prime} 10^{\prime \prime}$ ), from July 13-16, 2015 (Fig. 1).

\subsection{Animal collection}

Kellet's whelks associate with rock-sand interfaces found along the seaward edge of subtidal rocky reefs (Zacherl et al., 2003). This habitat typically occurs at $10-30 \mathrm{~m}$ depth and is often associated with the outer edge of kelp forests. We focused our collections in this habitat at each of the four sites at the Channel Islands. Adult Kellet's whelks were collected by hand using SCUBA from the sea floor and frozen whole with shell in liquid nitrogen within $15 \mathrm{~min}$ of being brought to the surface from each site. Whelks ranged in size from 88 to $105 \mathrm{~mm}$ in shell length and were collected at depths ranging from 9.1 to $28.4 \mathrm{~m}(9.1-23.5 \mathrm{~m}$, 15.2-28.4 m, 15.2-21.3 m, and 13.7-19.8 m at Anacapa, Santa Cruz, Santa Rosa, and San Miguel Island sites, respectively). Both male and female whelks were collected and analyzed. Collected whelks were taken to California Polytechnic State University, San Luis Obispo and 
maintained at $-80^{\circ} \mathrm{C}$ until dissection. Maintaining the whelks frozen during dissection allowed for the shells to be easily broken and ensured that the gill tissue was identifiable from mantle. Frozen whelks were dissected by breaking the shell using a vise and the gill tissue was isolated quickly on ice to minimize defrosting. Gill was identified by the feather-like ctenidia and texture, which distinguished it from mantle tissue. The gill was used for proteomic analysis because it is the major site of respiration and is in direct contact with the environment, and thus is expected to exhibit a strong proteomic response relative to other tissues. Animal collection followed guidelines approved by the California Department of Fish and Wildlife (permit \#SCP-8018 issued to C.W.). This study followed California Polytechnic State University Institutional Animal Care and Use Committee policies, which exempt invertebrates from research regulations.

\subsection{Temperature data}

Long-term subsurface temperature data from the Partnership for the Interdisciplinary Studies of Coastal Oceans (PISCO) were obtained from the nearest temperature measurement site at each respective island and animal collection location (Fig. 1). Temperature data at each site were measured using an Onset HOBO Tidbit logger moored near the ocean bed in a nominal depth of approximately $14 \mathrm{~m}$. We assume that these near-bottom temperature measurements (14 $\mathrm{m}$ depth; $20 \mathrm{~min}$ time interval) are representative of the subsurface temperature conditions in the depth ranges of where the animals were collected (depths ranging from 9.1 to $28.4 \mathrm{~m}$ ), as well as the thermal gradients present across the island sites (see also the temperature climatology described below).

Protein expression related to acute thermal stress can reach maximal levels $1-3 \mathrm{~h}$ or $15-30 \mathrm{~h}$ after stress exposure (depending on species tolerance) and changes in protein abundance are evident after long term (several weeks) cold acclimation in marine molluscs (Fields et al., 2012; Tomanek and Somero, 2000). Thus, to identify protein abundance changes related to thermal stress occurring during acute and long-term exposure, we focused our analysis on the temperature data to one day before whelk collection (i.e., acute exposure) and three-weeks before collection (i.e., long-term acclimatization) (Fig. 2). Additionally, long-term sea surface temperature (SST) climatology data from 2003 to
2014 were obtained from a daily, level 4 blended climatological product (i.e., long-term mean calculated using all daily MUR SST data from 2003 to 2014) produced on a $0.011^{\circ}$ grid (JPL MUR MEaSUREs Project, 2015) (Fig. 1).

\subsection{Thermal environment characterization}

Long-term SST shows the surface thermal gradient trending from the coolest site at San Miguel Island to the warmest site at Anacapa Island, with Santa Cruz and Santa Rosa Islands at intermediate temperatures (Fig. 1). The subtidal temperatures measured near the collection sites within one-day and within three-weeks prior to the collection of the animals both display a similar trend (Fig. 2). However, there are instances within the three-week period where subtidal temperatures measured at each collection site do not follow the long-term SST thermal gradient trend. For example, immediately prior to collecting the whelks (time before collection $0 \mathrm{~d}$ ), mean subtidal temperatures measured at Santa Cruz are colder than those measured at San Miguel, and there are instances where Santa Cruz mean subtidal temperatures are warmer than Santa Rosa (time before collection 0.6-0.5 and $0.8 \mathrm{~d}$ ) (Fig. 2B). In addition, over a longer time period of $21 \mathrm{~d}$ there is a greater variation in temperature observed at San Miguel and Santa Cruz Islands compared to Santa Rosa or Anacapa (Fig. 2A).

However, on average, Anacapa Island experienced the warmest temperatures ( $\quad{ }^{\circ} \mathrm{C}$, where is mean temperature calculated over a one-day time window prior to collection at each respective site), San Miguel the coldest ( $\left.\quad{ }^{\circ} \mathrm{C}\right)$, and Santa Cruz $\left({ }^{\circ} \mathrm{C}\right)$ and Santa Rosa ( $\quad{ }^{\circ} \mathrm{C}$ ) were at intermediate temperatures. The thermal variability over the day prior to collection, as measured by the standard deviation $(\sigma)$ of the one-day time window, was highest at San Miguel $\left(\sigma=1.02^{\circ} \mathrm{C}\right)$, followed by Santa Cruz $\left(\sigma=0.96^{\circ} \mathrm{C}\right)$, Santa Rosa $\left(\sigma=0.83^{\circ} \mathrm{C}\right)$, and Anacapa $\left(\sigma=0.28^{\circ} \mathrm{C}\right)$ Islands.

\subsection{Proteomics}

\subsubsection{Homogenization}

Frozen gill tissue was thawed and lysed in a ratio of $1: 4$ of tissue to homogenization buffer $\left[7 \mathrm{moll}^{-1}\right.$ urea, $2 \mathrm{moll}^{-1}$ thiourea, $1 \%$ ASB- 14

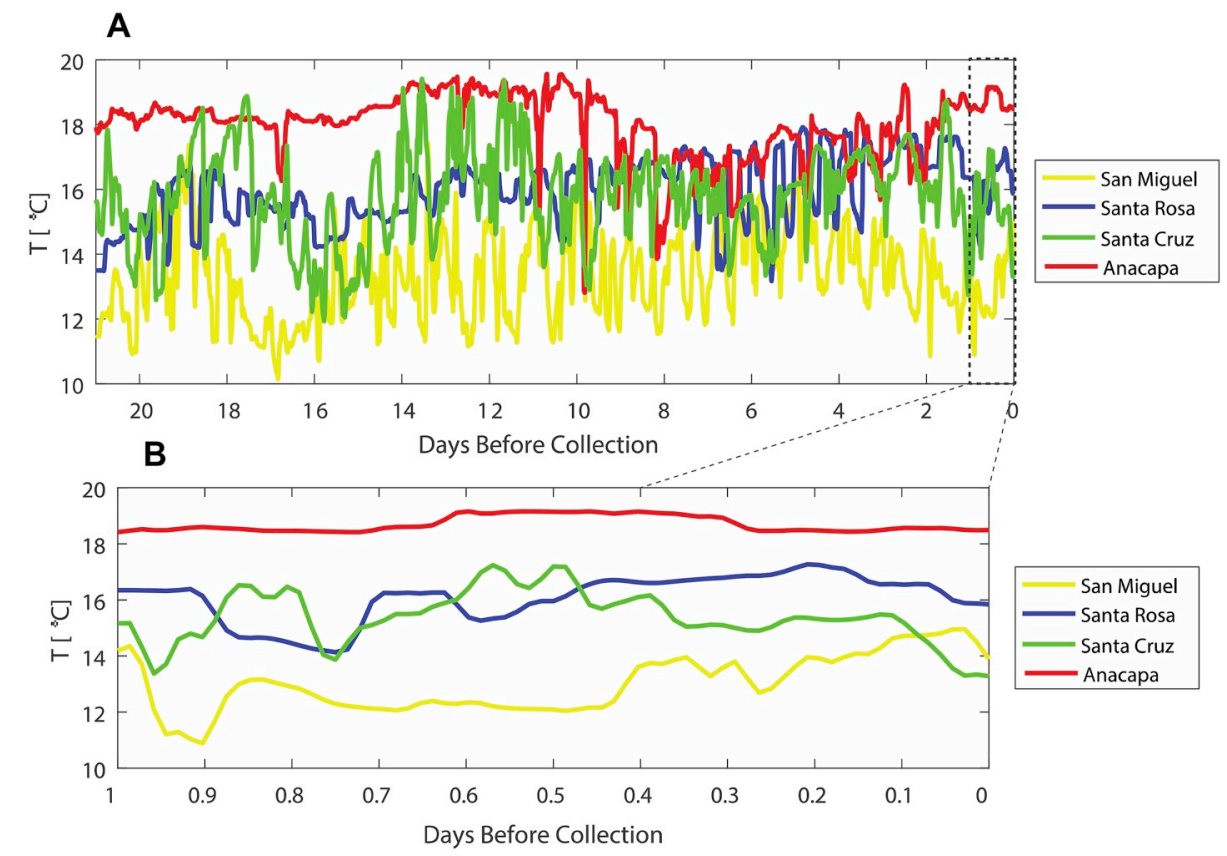

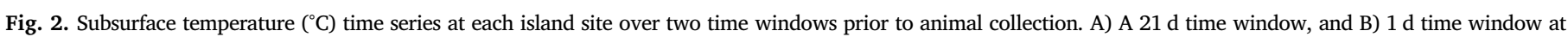
each respective site. Mean temperature and standard deviation over the one-day window prior to collection for each site was: San Miguel ( Santa Rosa ( $\quad{ }^{\circ} \mathrm{C}, \sigma=0.83{ }^{\circ} \mathrm{C}$ SD), Santa Cruz ( $\quad{ }^{\circ} \mathrm{C}, \sigma=0.96{ }^{\circ} \mathrm{C}$ SD) and Anacapa $\left(\quad{ }^{\circ} \mathrm{C}, \sigma=0.28{ }^{\circ} \mathrm{C}\right.$ SD). 
(amidosulfobetaine-14), $40 \mathrm{mmol}^{-1}$ Tris-base, 0.5\% immobilized $\mathrm{pH}$ 3-10 gradient (IPG) buffer (GE Healthcare, Piscataway, NJ, USA) and $40 \mathrm{mmoll}^{-1}$ dithiothreitol], using an ice-cold ground-glass homogenizer. The homogenate was subsequently centrifuged at room temperature for $30 \mathrm{~min}$ at $16,100 \mathrm{~g}$ and the supernatant was used for further processing. Proteins of the supernatant were precipitated by adding four volumes of ice-cold $10 \%$ trichloroacetic acid in acetone and incubating the solution at $-20{ }^{\circ} \mathrm{C}$ overnight. After centrifugation at $4{ }^{\circ} \mathrm{C}$ for $15 \mathrm{~min}$ at $18,000 \mathrm{~g}$, the supernatant was discarded and the remaining pellet was washed with ice-cold acetone, and centrifuged again before being re-suspended in rehydration buffer $\left[7 \mathrm{moll}^{-1}\right.$ urea, $2 \mathrm{moll}^{-1}$ thiourea, 2\% CHAPS (cholamidopropyl-dimethylammonio-propanesulfonic acid), 2\% NP-40 (nonyl phenoxylpolyethoxylethanol-40), $0.002 \%$ Bromophenol Blue, 0.5\% IPG buffer and $100 \mathrm{mmoll}^{-1} \mathrm{di}$ thioerythritol] through vortexing. The rehydrated protein pellet became the precipitated protein solution used for quantification of protein concentration and in gel electrophoresis. The protein concentration was determined with the 2D Quant kit (GE Healthcare), according to the manufacturer's instructions.

\subsubsection{Two-dimensional gel electrophoresis (2DGE)}

Proteins $(400 \mu \mathrm{g})$ were loaded onto IPG strips (pH 5-8, $11 \mathrm{~cm}$; GE Healthcare) by pipetting on top of the length of the strip for separation according to their isoelectric point (pI). We started the isoelectric focusing protocol with a passive rehydration step $(5 \mathrm{~h})$, followed by $12 \mathrm{~h}$ of active rehydration $(50 \mathrm{~V})$, using an isoelectric focusing cell (BioRad, Hercules, CA, USA). The following protocol was used for the remainder of the run (all voltage changes occurred in rapid mode): $500 \mathrm{~V}$ for $1 \mathrm{~h}$, $1000 \mathrm{~V}$ for $1 \mathrm{~h}$, and $8000 \mathrm{~V}$ for $2.5 \mathrm{~h}$. The strips were frozen at $-80^{\circ} \mathrm{C}$.

Frozen strips were thawed and incubated in equilibration buffer [375 $\mathrm{mmol}^{-1}$ Tris-base, $6 \mathrm{moll}^{-1}$ urea, 30\% glycerol, 2\% SDS (sodium dodecyl sulfate) and $0.002 \%$ Bromophenol Blue] for $15 \mathrm{~min}$, first with $65 \mathrm{mmoll}^{-1}$ dithiothreitol and then, second with $135 \mathrm{mmoll} \mathrm{l}^{-1}$ iodoacetamide. IPG strips were placed on top of a $12 \%$ polyacrylamide gel with a $0.8 \%$ agarose solution containing Laemmli SDS electrophoresis (or running) buffer $\left(25 \mathrm{mmoll}^{-1}\right.$ Tris-base, $192 \mathrm{mmoll}^{-1}$ glycine and $0.1 \%$ SDS). Gels were run (Criterion Dodeca; BioRad) at $200 \mathrm{~V}$ for $55 \mathrm{~min}$ with a recirculating water bath set at $10^{\circ} \mathrm{C}$. Gels were subsequently stained with colloidal Coomassie Blue (G-250; BioRad) overnight and destained by washing repeatedly with Milli-Q (Millipore, Billerica, MA, USA) water for $48 \mathrm{~h}$. The resulting gel images were scanned with a transparency scanner (model 1280; Epson, Long Beach, CA, USA). Gels were run once per sample (total of 24 gels).

\subsubsection{Gel image analysis}

Digitized 2D gel images were analyzed using Delta 2D (version 3.6; Decodon, Greifswald, Germany; Berth et al., 2007). To detect protein spots, gels from each whelk across all island sites were multiplexed into a single composite image using the group warping strategy to connect gel images through match vectors (Fig. 3). Spots were detected automatically using Delta 2D and a spot detection sensitivity set to $10 \%$ to minimize detection of noisy background artifacts. After automated detection, spots were quality checked manually to add and eliminate spots using the 3D Spot Rollups tool in Delta 2D, which visualizes spot pixel density in three-dimensional space by modeling the spot's intensity as a Gaussian normal distribution (Berth et al., 2007). Spots were considered for analysis if they were present in the composite image and were verified as spots using the 3D Spot Rollups tool. Nine spots that were identified on the composite image were not found on seven of the gels, nonetheless, they remained within the analysis. We detected a total of 297 protein spots from the composite image (Fig. 3). The spot boundaries detected on the composite image were transferred back to the individual gels using match vectors, establishing protein spot parameters for each gel. Following background subtraction, the relative spot volume of each protein was quantified by normalization against the total spot volume of all proteins in the gel image (Tomanek and Zuzow, 2010) (Fig. 3). In the instance that a spot was not present on a gel but included in the composite image, the abundance value was accepted as zero.

\subsubsection{Mass spectrometry}

Protein spots that differed in abundance between the islands (60 spots) were manually excised from several gels representing whelks from the four island sites using a tissue puncher. If a spot was faint, it was excised from two gels of the same sample and pooled. Spots that were not identified during the initial analysis were excised again and re-run a second time. Gel plugs were prepared for analysis using mass spectroscopy (MS) according to previously published methods (Fields et al., 2012; Tomanek and Zuzow, 2010; Vasquez et al., 2017). Briefly, following excision, spots were destained and digested with $11 \mathrm{ng} \mu \mathrm{l}^{-1}$ of trypsin (Promega, Madison, WI, USA). Digested proteins were extracted using elution buffer [0.1\% trifluoroacetic acid (TFA)/acetonitrile; $2: 1$ ] and concentrated using a SpeedVac (Thermo Fisher Scientific, Waltham, MA, USA). The elution buffer containing the digested protein was mixed with $5 \mu \mathrm{l}$ of matrix solution $\left(0.2 \mathrm{mg} \mathrm{ml}^{-1} \alpha\right.$-hydroxycyano cinnamic acid in acetonitrile) and spotted on an Anchorchip ${ }^{\mathrm{TM}}$ target plate (Bruker Daltonics Inc., Billerica, MA, USA).

Peptide mass fingerprints (PMFs) were obtained using a matrix-assisted laser desorption/ionization tandem time-of-flight (MALDI-ToFToF) mass spectrometer (UltraFlex II; Bruker Daltonics, Inc.; Billerica, MA, USA). To obtain b- and y-ion parameters, at least 6 peptides were selected for analysis.

Spectral analysis of peptides followed previously published methods (Fields et al., 2012; Tomanek and Zuzow, 2010). FlexAnalysis (version 3.0; Bruker Daltonic, Inc.) was used to detect peptide peaks, and applied the TopHat algorithm for baseline subtraction, the Savitzky-Golay analysis for smoothing (with: $0.2 \mathrm{~m} / z$; number of cycles $=1$ ) and the SNAP algorithm to detect peaks (signal-to-noise ratio: 6 for MS and 1.5 for MS/MS). The charge state of the peptides was assumed to be +1 . Internal mass calibration was performed using porcine trypsin.

Proteins were identified using Mascot (version 2.4; Matrix Science, Inc.; Boston, MA). PMFs and tandem mass spectra were combined and searched against taxonomic databases constructed from the NCBI taxonomy browser (http://www.ncbi.nlm.nih.gov/Taxonomy/) (Federhen, 2012). Specifically, we used the Gastropoda expressed sequence tag (EST) and protein sequence databases (containing 3820464 and 209979 sequences, respectively; NCBI:txid6448) as well as an EST and protein sequence database for Mollusca, (containing 6832416 and 408597 sequences, respectively; NCBI:txid6447). If no match was found, a final search was conducted using NCBInr (metazoan) containing 9560026 sequences (NCBI:txid33208). One missed cleavage was allowed during searches and oxidation of methionine and carbamidomethylation of cysteine were our only variable modifications. For the MS/MS analysis, the precursor-ion mass tolerance was set at $0.6 \mathrm{Da}$ (default Mascot value). Search results were deemed significant $(P \leq 0.05)$ if their molecular weight search (MOWSE) score was 42 or higher in a search in the Gastropoda database or Mollusca database and included two matched peptides regardless of MOWSE score (supplementary information Table S1). The score in Mascot indicates significant homology $(P \leq 0.05)$ between the experimental peptide sequence and a database sequence match.

\subsection{Statistical analysis}

To determine significant changes in protein abundance for each protein spot across the four island sites where whelks were collected, we used a 1-way ANOVA $(P \leq 0.05)$. We generated a null distribution for the 1-way ANOVA (1000 permutations) to account for unequal variance and non-normal distributions of the response variables (Delta2D). From this analysis, we found 60 protein spots $(20 \%$ of the total 297 spots) changed abundance with island location, and we identified 28 of the significantly changing proteins using tandem mass 


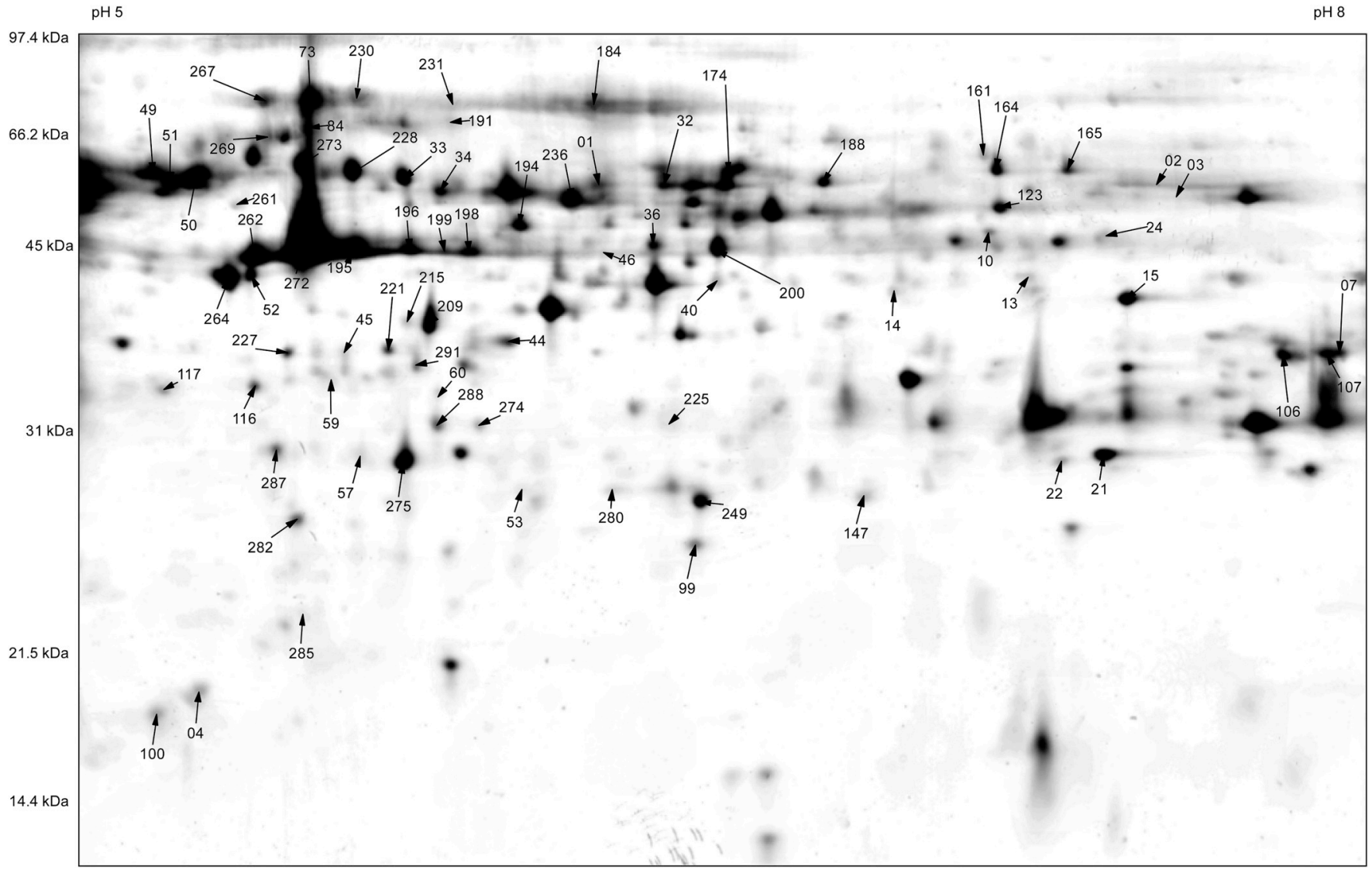

Fig. 3. Composite gel image (proteome map) from 24 gels (six individuals from each of the four island sites) showing 297 protein spots from gill tissue of the Kellet's whelk (Kelletia kelletii). The proteome map represents average pixel volumes for each protein spot. Numbered spots are those that changed abundance in response to island location (one-way permutation ANOVA; $P \leq 0.05$ ) and non-significant proteins that were positively identified using tandem mass spectrometry (for identification see supporting information Table S1).

spectrometry (Table S1). Post-hoc testing to compare protein abundances between island sites was conducting using Tukey's analysis $(P \leq 0.05)$ in Minitab (v. 16.1.1, Minitab Inc., State College, PA, USA) (Figs. S1-S3). It should be noted that an FDR correction was not used and we have accepted the probability of Type I error in our analysis. More often than not, it is the case that environmental proteomic studies do not incorporate FDR corrections into their analysis, as seen in a review by Dowd (2012) where none of the 31 studies reviewed used an FDR correction but opt for a more stringent critical p-value. Additionally, of 166 2-D gel electrophoresis studies published in three proteomic journals (2009-2010 in Molecular and Cellular Proteomics, Journal of Proteome Research, Proteomics), nearly 90\% did not use an FDR correction (Diz et al., 2011). A Bonferroni correction may be too stringent for proteomics studies (in our study $P=0.05 / 297=0.00017$ ) and may result in missed significant effects. While there exist alternative FDR corrections for proteomics data sets, like Benjamini-Hochberg (Benjamini and Hochberg, 1995) or the calculation of a q-value statistic (Storey and Tibshirani, 2003), there is still a risk of failing to identify true protein abundances changes, especially when effect sizes are small (Pascovici et al., 2016). Therefore, since the nature of our study is exploratory and preliminary, we did not include an FDR correction in order to elucidate potential protein targets for follow-up investigations in Kellet's whelks. That is, we consider the results from this study to represent hypotheses that could be tested by future studies with higher statistical power and/or more controlled experimental designs.

To associate proteins with similar changes in abundance across samples, we employed hierarchical clustering with average linking (Delta2D), using a Pearson correlation metric. To further assess the importance of specific proteins in differentiating the proteomes of whelks located across the four island sites, we employed principal component analysis (PCA; Delta2D) based on proteins whose abundances changed significantly during and after treatment exposure (1way ANOVA, $P \leq 0.05$ ).

\section{Results}

\subsection{Principal component analyses}

The first principal component (PC1), which explained 23\% of the variation, separated Anacapa from Santa Rosa Islands along the $\mathrm{x}$-axis, while Santa Cruz and San Miguel Islands were similarly located (Fig. 4). PC2, which explained $19.7 \%$ of the variation, separated Santa Cruz from the other three islands, which were all similarly located along the $y$-axis (Fig. 4). Therefore, these results suggest that changes in protein abundance differ in whelks from Anacapa Island compared to Santa Rosa Island, and whelks from Santa Cruz Island express different protein abundance patterns in comparison to whelks from the other three islands. Interestingly, we expected separation of island sites along PC1 with the warmest (Anacapa) and coolest (San Miguel) island sites located at opposite ends of the x-axis; however, this was not the case, as these two islands were actually located adjacent to each other (Fig. 4).

\section{Discussion}

To assess the contribution of the cellular processes associated with the function of specific proteins, we grouped proteins into the following functional categories: cytoskeleton and cell signaling, and energy 


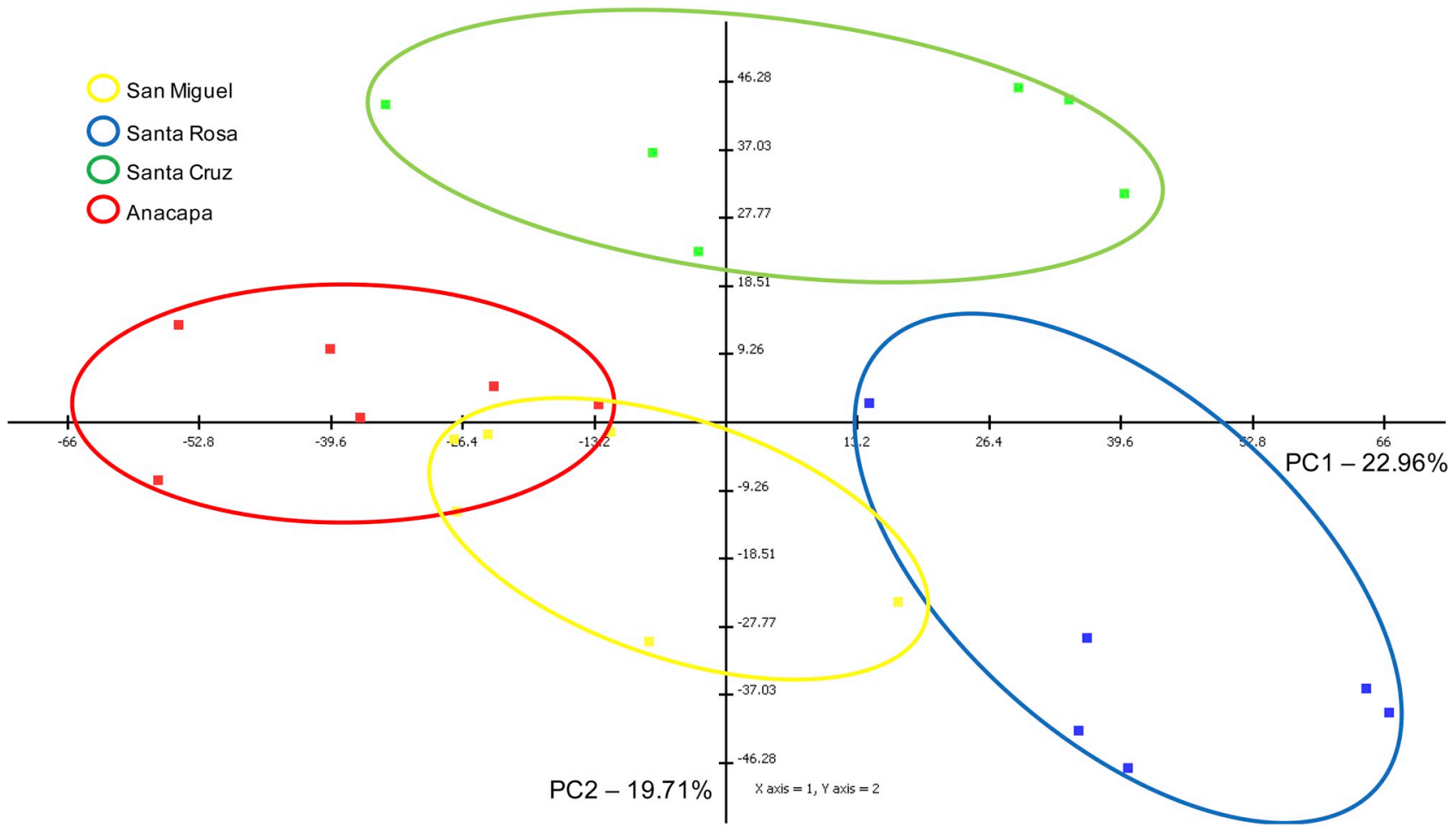

Fig. 4. Principal component analysis (PCA) based on proteins that showed significant effects (one-way permutation ANOVA; $P \leq 0.5$ ) based on island site where Kellet's whelks (Kelletia kelletii) were collected. Each symbol represents a whelk collected from San Miguel (yellow), Santa Rosa (blue), Santa Cruz (green), or Anacapa (red) Island sites. Principle components 1 and 2 (PC1 and PC2) and the percentage of the total variation of the selected (significant protein) data set they explain are shown. See text for explanation of PC1 and PC2. (For interpretation of the references to color in this figure legend, the reader is referred to the Web version of this article.)

metabolism and oxidative stress. We also assessed PC loading values, which quantify the contribution of each protein in the separation of samples along a given component and provide an exploratory assessment of the possible changes that accompany the separation of treatment groups.

\subsection{Cytoskeleton and cell signaling}

Of the 28 proteins identified, 15 (53\%) were related to the cytoskeleton (Fig. 5). In general, proteins in cluster I (myosin-10, three isoforms of actin) had greater protein abundance from whelks at Anacapa Island compared to Santa Rosa Island (Fig. 5, S1). These proteins

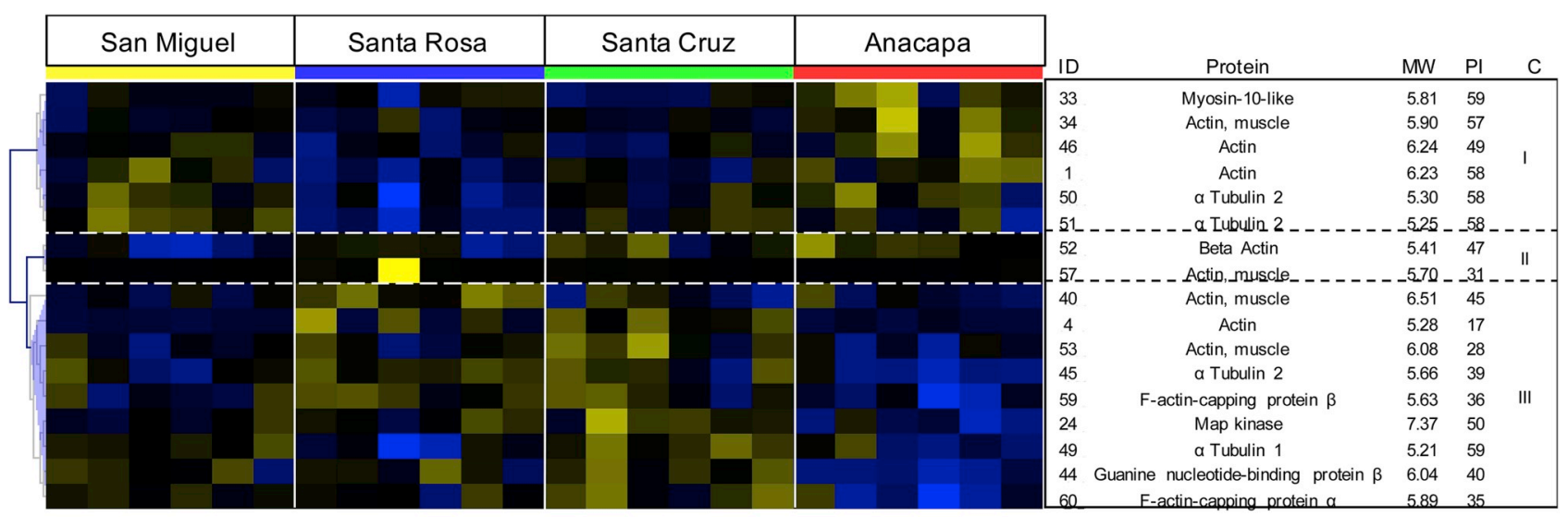

Protein Abundance Changes

$-0.22$

4.68

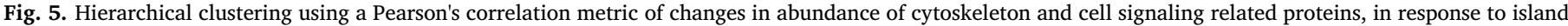

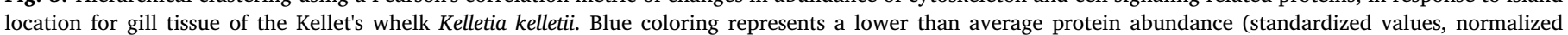

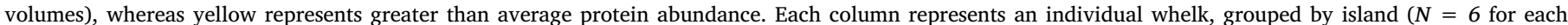

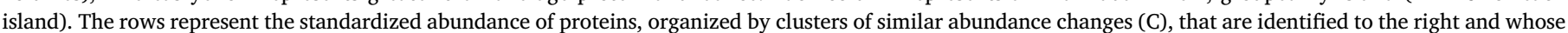

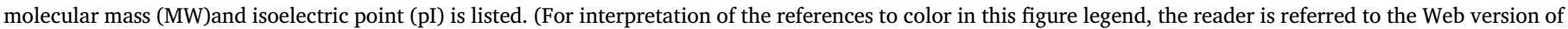
this article.) 
Table 1

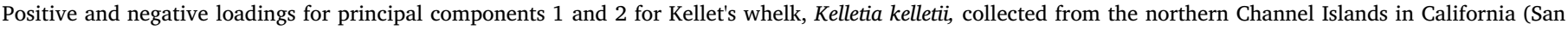
Miguel, Santa Rosa, Santa Cruz, and Anacapa).

\begin{tabular}{|c|c|c|c|c|}
\hline \multirow[t]{2}{*}{ Component Loading Rank } & \multicolumn{2}{|l|}{ Principal Component 1} & \multicolumn{2}{|l|}{ Principal Component 2} \\
\hline & Protein (Spot ID) & Loading Value & Protein (Spot ID) & Loading Value \\
\hline \multicolumn{5}{|l|}{ Positive Loadings } \\
\hline 1 & Triosephosphate isomerase (21) & 1.78357 & ATP synthase subunit alpha (3) & 1.42415 \\
\hline 2 & Alpha Tubulin 2 (45) & 1.71295 & ATP synthase subunit alpha (2) & 1.39828 \\
\hline 3 & F-actin-capping protein subunit beta (59) & 1.6786 & Tubulin alpha 1 (49) & 1.27869 \\
\hline 4 & Arginine kinase (15) & 1.44722 & Actin, muscle (53) & 1.1963 \\
\hline 5 & Actin (4) & 1.38709 & Beta Actin $1(52)$ & 0.95569 \\
\hline 6 & GTP:AMP phosphotransferase AK3 (22) & 1.25728 & F-actin-capping protein subunit alpha (60) & 0.88802 \\
\hline 7 & Actin, muscle (53) & 1.23155 & Map kinase (24) & 0.85359 \\
\hline 8 & Actin, muscle (40) & 1.22269 & Alpha Tubulin 2 (51) & 0.66784 \\
\hline 9 & Map kinase (24) & 1.09525 & Alpha Tubulin $2(50)$ & 0.57802 \\
\hline 10 & Malate dehydrogenase (7) & 1.0264 & Guanine nucleotide binding protein (44) & 0.56861 \\
\hline \multicolumn{5}{|l|}{ Negative Loadings } \\
\hline 1 & Alpha Tubulin 2 (50) & -1.66508 & Citrate synthase (10) & -2.03162 \\
\hline 2 & Actin (46) & -1.58042 & Cystathione gamma-lyase (13) & -1.61228 \\
\hline 3 & Aldehyde dehydrogenase (32) & -1.47245 & Malate dehydrogenase (7) & -1.22406 \\
\hline 4 & Alpha Tubulin 2 (51) & -1.38024 & Pyruvate dehydrogenase E1 (14) & -1.14442 \\
\hline 5 & Actin (1) & -1.30246 & NADP Isocitrate dehydrogenase (36) & -1.03205 \\
\hline 6 & Myosin $10(33)$ & -1.28569 & GTP:AMP phosphotransferase AK3 (22) & -0.96227 \\
\hline 7 & NADP Isocitrate dehydrogenase (36) & -1.20046 & Actin, muscle (40) & -0.83539 \\
\hline 8 & Actin, muscle (34) & -1.07661 & Actin, muscle (57) & -0.80806 \\
\hline 9 & Tubulin alpha (49) & -0.17126 & Triosephosphate isomerase (21) & -0.69928 \\
\hline 10 & ATP synthase subunit alpha (3) & -0.03407 & Aldehyde dehydrogenase (32) & -0.47245 \\
\hline
\end{tabular}

also all showed high negative loading values for PC1, suggesting that the decrease in protein abundance observed at Santa Rosa Island contributed to separation of Santa Rosa Island along PC1 (Fig. 4 and Table 1). Myosin-10 is an unconventional myosin that functions in filopodia formation, plasma membrane signaling, and as an actin-based motor protein (Berg and Cheney, 2002; Berg et al., 2000), while actin has many cellular functions including cell division, motility, signaling, contraction and maintaining cell shape. Cytoskeletal stability is compromised under thermal stress and increased actin protein abundance suggests possible cytoskeletal rearrangement and formation of stress fibers/aggregates (Tomanek, 2014). This is often observed in combination with increased small heat shock protein abundance (sHSPs) as a method to stabilize cytoskeletal protein conformation (none identified in our study), and as a result of reactive oxygen species (ROS) (Mounier and Arrigo, 2002; Tomanek and Zuzow, 2010). The mean subsurface seawater temperature at Anacapa Island was $2.6-5.7^{\circ} \mathrm{C}$ greater in comparison to the other island sites (Fig. 2). Thus, it is possible that the warmer environment at Anacapa Island could influence cytoskeletal protein dynamics resulting in greater myosin and actin isoform abundance in whelks collected at Anacapa Island.

Two additional proteins in cluster I (two isoforms of $\alpha$-tubulin) tended to have the opposite effect where greater protein abundance was observed at San Miguel Island compared to Santa Rosa (Fig. 5, S1). These proteins also showed high negative loading values for PC1, suggesting that the decrease in protein abundance observed at Santa Rosa Island for $\alpha$-tubulin contributed to separation of Santa Rosa Island along PC1 (Fig. 4 and Table 1). Microtubules, comprised of tubulin, participate in cell structure, transport, and mitosis, and microtubule assembly is promoted at temperatures to which the organism is adapted (Wallin and Strömberg, 1995). Increased $\alpha$-tubulin protein abundance could assist in microtubule formation under the cooler thermal environment found at San Miguel Island and the warmer historic thermal environment at Anacapa, which also had increased $\alpha$-tubulin protein abundance (but was not significantly different from San Miguel). Increases in tubulin abundance may be a result of thermal stress altering cytoskeleton structure and thereby tubulin dynamics (Fields et al., 2012; Tomanek, 2014).

Tubulin post-translational modifications (PTMs) may affect microtubule dynamics by regulating effectors that act on the microtubule to influence turnover (Hammond et al., 2008; Verhey and Gaertig, 2007). Proteomics allows us to identify possibly modified proteins indicated by shifts in isoelectric point (pI). In total, three isoforms of $\alpha$-tubulin were identified each with the pI shifted by only 0.05 or 0.09 pI units (spot\#50 compared to 51 and 49, respectively), and these isoforms also showed protein abundance changes that were influenced by island site (Fig. 5). PTMs in tubulin include polyglutamylation, polyglycylation, tyrosination, phosphorylation, and acetylation (Ludeña, 1997). It is possible that the variation in $\alpha$-tubulin pI observed (and thus PTMs) may be a method for enhancing microtubule stability depending on thermal environment. Long term (four-week) acclimation of marine molluscs (Mytilus trossulus and M. galloprovincialis) to cold $\left(7\right.$ or $\left.13^{\circ} \mathrm{C}\right)$ results in upregulation of actin and tubulin isoforms (Fields et al., 2012). Fields et al. (2012) attributed the changes in abundance of actin and tubulin during cold exposure to two proteins, T-complex protein 1 (TCP-1) and radial spoke head 9 proteins. The concomitant increase in these proteins may function to assist in folding of cytoskeletal proteins (like actin and tubulin) suggesting alterations in gill cilia/structure at lower temperatures (Fields et al., 2012). However, we did not identify either TCP-1 or radial spoke head 9 protein in Kellet's whelk, but this does not exclude the possibility that cytoskeletal structural changes are occurring in whelk gill under variable thermal exposure.

Proteins in cluster II ( $\beta$-actin and actin) showed different patterns of protein abundance compared to proteins in cluster III. $\beta$-actin, a cytoskeleletal structural protein, showed the greatest abundance in whelks from Anacapa Island compared to San Miguel (Fig. 5, S1), while actin (spot\#57) showed no significant pairwise differences in protein abundance among the four island sites (Tukey HSD, $P>0.050$; Fig. S1). In long term acclimated $\left(19^{\circ} \mathrm{C}\right)$ mussels (M. galloprovincialis and $M$. trossulus) protein abundance of cytoskeletal proteins, like actin, $\alpha$-tubulin, and $\beta$-tubulin, both increased and decreased under chronic heat stress (Fields et al., 2012). Increased abundance may be due to increased ciliary activity for feeding/respiration in warmer environments (Fields et al., 2012). However, it is unclear which role these tubulin isoforms play in the gill of Kellet's whelks.

Proteins in cluster III tended to have lower protein abundance from whelks at Anacapa compared to Santa Cruz Island (actin spot\#53, two isoforms of $\alpha$-tubulin, two isoforms of F-actin capping protein) (Fig. 5, S1). Both F-actin capping protein isoforms identified had a $50 \%$ 
decrease in protein abundance at Anacapa Island compared to Santa Cruz (Fig. S1). F-actin capping protein blocks the growing end of actin filaments thereby reducing filament growth (Weeds and Maciver, 1993). Thus, the decrease at Anacapa Island may allow for actin filament growth necessary for cytoskeletal rearrangement under temperature stress (Tomanek, 2011).

A second isoform of actin (spot\#40) showed greater protein abundance in whelks obtained from Santa Rosa Island compared to the other three islands (Fig. 5, S1). The difference in molecular weight and pI by $0.43 \mathrm{pI}$ units of the two actin isoforms (spot\#40 and \#53) suggest a possible PTM influencing the observed protein abundance responses. Major actin PTMs include acetylation, ADP-ribosylation, arginylation, O-GlcNAcylation, methylation, oxidation, phosphorylation, and ubiquitylation, with each influencing actin functionality and regulation (Terman and Kashina, 2013). Although it is not clear what type of PTM the isoforms of actin identified in our study may have, our findings suggest a role for PTMs in regulating actin function under the different thermal environments found at each island site.

In summary, our study provides initial evidence that Kellet's whelks from Anacapa Island are responding to warmer thermal environments by increasing cytoskeletal proteins necessary for cytoskeletal dynamics and stability (actin, myosin) and decreasing acting binding proteins that limit filament growth (F-actin binding protein) necessary for rearrangement under possible heat stress. Microtubule stability may be enhanced by PTMs and greater tubulin protein abundance may be most important at cooler (San Miguel) and warmer (Anacapa) environments to maintain stability. However, we are far from understanding the dynamic shifts in abundance of particular isoforms of cytoskeletal proteins and their possible PTMs in stabilizing and/or enhancing macromolecular assemblies and function, and our study provides hypotheses and possible cytoskeletal targets for further analysis in future studies investigating thermal effects on the proteome of Kellet's whelk.

\subsection{Cell signaling}

We identified two cell signaling proteins, ERK2 MAPK and guanine nucleotide binding protein (G-protein) (Fig. 5). In general, protein abundance tended to be lowest in whelks collected from Anacapa Island and greatest in whelks from the other three sites (Fig. 5, S2). ERK2 MAPK functions to phosphorylate, and thereby activate, the cascading signal of a number of cellular processes, including cell cycle progression, cell survival, differentiation, metabolism, proliferation, adhesion, and transcription (Roskoski, 2012). G-proteins are molecular switches that control cellular processes including cell growth and differentiation, and vesicular and nuclear transport (Vetter and Wittinghofer, 2001). Physiological effects of cold stress often include inhibition of transcription and translation, reduction in protein synthesis, and slowing of cell cycle progression (especially at G1) (Hochachka and Somero, 2002; Sonna et al., 2002). Previous studies in mammalian cells have shown that cold stress can activate the cell stress response signaled by MAPK phosphorylation, but stress protein expression only occurs during rewarming following cold exposure (Sonna et al., 2002). The increased protein abundance of the identified cell signaling proteins in whelks from the relatively cooler island sites suggests a possible requirement for increased regulation of cellular signaling, possibly to mediate inhibited transcription and/or translation by lower environmental temperatures and facilitate cellular stress response signaling by MAPK, but these are hypotheses requiring further investigation in follow-up Kellet's whelk studies.

\subsection{Energy metabolism and oxidative stress}

\subsubsection{Energy metabolism}

Two isoforms of ATP synthase (Fig. 6, cluster I) showed a trend toward greater protein abundance at Santa Cruz Island in comparison to Anacapa/San Miguel (spot\#2) or Santa Rosa (spot\#3) (Fig. 6, S3). Both isoforms of ATP synthase also showed high positive loading values for PC2, indicating their contribution in separating Santa Cruz Island from the other island sites (Fig. 4, Table 1). Conversely, protein abundance of the tricarboxylic acid (TCA) cycle proteins citrate synthase, pyruvate dehydrogenase (PDH), and NADP isocitrate dehydrogenase (IDH) decreased at Santa Cruz Island but was greater at San Miguel and Santa Rosa Islands. In addition, these proteins had high negative loading values for PC2 (Fig. 6, S3 and Table 1). Increased protein abundance of ATP synthase in whelks from Santa Cruz Island may dissipate the proton gradient altering proton motive force across the mitochondrial membrane more than in whelks from the other locations. However, as we do not know the enzyme activity of ATP synthase or the concentration of ATP (the allosteric modulator of citrate synthase, $\mathrm{PDH}$ and IDH; Chandel, 2015) in the whelks sampled, it is difficult to determine the effect of our findings on other proteins. If higher ATP synthase levels lead to higher ATP levels, they would possibly decrease the activity of citrate synthase, PDH and IDH through allosteric modulation. This needs to be confirmed through more targeted studies.

Mitochondrial malate dehydrogenase (mMDH) reduces $\mathrm{NAD}^{+}$to NADH used by the electron transport system (ETS) complex I to produce ATP. MDH can also convert oxaloacetate to malate in the mitochondria so it can then be transported out to the cytosol (with the malate-aspartate shuttle) and used in gluconeogenesis (Somero et al., 2017). Gluconeogenesis is tightly regulated and therefore glycolysis is concurrently down-regulated (Chandel, 2015). We observed a greater protein abundance of mMDH in whelks from Santa Rosa Island compared to the other three island sites, and it is most likely that mMDH functions to produce NADH necessary for ATP production, rather than gluconeogenesis, as we also saw increased protein abundance of PDH (Fig. 6, S3). In addition, arginine kinase (AK) functions as a phosphagen kinase enzyme used to catalyze the transfer of phosphate from phosphagens such as phosphoarginine, thereby assisting in ATP buffering (Ellington, 2001). AK showed a trend towards greater protein abundance at Santa Rosa Island compared to Anacapa, possibly indicating a greater energy need in whelks from relatively cooler environments (Fig. 6 and S2).

In summary, we provide initial evidence of greater energy production and regulation in whelks from the cooler island sites (San Miguel and Santa Rosa) compared to whelks from Anacapa Island. Greater ATP production may signal metabolic compensation as a result of changing thermal environments. In the marine gastropod Littorina saxatilis, cold acclimation $\left(4^{\circ} \mathrm{C}\right.$ compared to the control at $\left.13^{\circ} \mathrm{C}\right)$ resulted in elevated aerobic metabolic rates, which may help maintain high activity levels under cold environments (Sokolova, 2003). Winter acclimatized Rainbow trout (Onchorhynchus mykiss) $\left(1{ }^{\circ} \mathrm{C}\right.$ compared to $\left.16{ }^{\circ} \mathrm{C}\right)$ show greater mitochondrial enzyme levels and cristae surface density (StPierre et al., 1998). Thus, we hypothesize that increased oxidative phosphorylation in response to cooler environments may be due to increased mitochondrial volume density and capacity. This in conjunction with increased protein abundance of AK may aid in providing sufficient ATP necessary to maintain activity levels under cooler environments.

\subsubsection{Oxidative stress}

Cold acclimation often induces changes in polyunsaturated fatty acid (PUFA) ratios to maintain membrane fluidity (Hazel, 1995). PUFAs are susceptible to ROS damage but this can be combatted by cellular antioxidants (Abele and Puntarulo, 2004). We would expect whelks from cooler sites (San Miguel and Santa Rosa Islands) to have higher concentrations of PUFAs and thus be at greater risk of ROS damage. In our study we observed changes in protein abundance indicative of possible antioxidant defense mechanisms to combat ROS damage to lipid membranes. Cystathionine $\gamma$-lyase can function in the cysteine synthesis pathway, which is required for the synthesis of the important antioxidant glutathione (Dilly et al., 2012; Tomanek, 2015). In whelks collected from cooler habitats (San Miguel and Santa Rosa Islands), we 


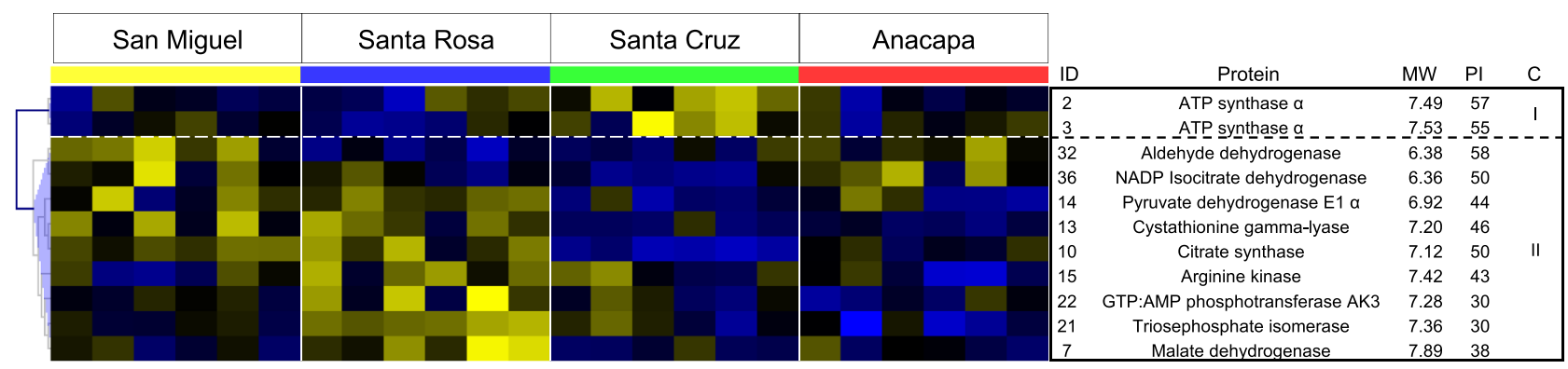

Protein Abundance Changes

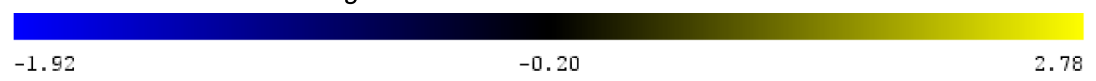

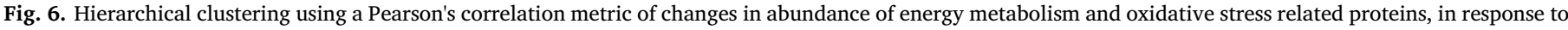
island site for gill tissue of the Kellet's whelk Kelletia kelletii. For additional details, see Fig. 5.

found a three-fold increase in protein abundance of cystathionine $\gamma$ lyase (Fig. 6, S3), suggesting possible ROS damage mediated by glutathione. NADP isocitrate dehydrogenase (NADP IDH), besides functioning in the TCA cycle, generates NADPH, a necessary reducing equivalent used by antioxidants to maintain cellular antioxidant capacity (Tomanek, 2015). Similarly, aldehyde dehydrogenase (ALDH2) functions to detoxify lipid peroxides (Grimsrud et al., 2008). Whelks collected from the island thermal extremes (San Miguel and Anacapa) showed the greatest NADP IDH and ALDH2 protein abundance (Fig. 6, S3). Likewise, long term (four-week) cold acclimated mussels ( $M$. trossulus and M. galloprovincialis, to 7 or $13^{\circ} \mathrm{C}$ ) also showed a significant upregulation in ALDH2 (Fields et al., 2012). This may provide initial evidence of oxidative stress and damage (i.e., lipid peroxidation) at under relatively cooler environments (Tomanek, 2015). These data suggest that there may be a cost, in the form of oxidative damage, to living in cooler habitats, such as that exhibited at San Miguel Island, but further analysis is necessary to elucidate this connection in whelks.

\subsection{Protein expression and thermal history}

In heat stressed intertidal snails of the genus Tegula, studies have shown synthesis of putative heat shock proteins occurring 1-3 h after heat stress during recovery and protein abundance returned to prestress levels after $6 \mathrm{~h}$. However, this response varies with species and intertidal location, as other Tegula congeners synthesize HSPs 2-14 h after stress reaching maximum $15-30 \mathrm{~h}$ afterwards (Tomanek and Somero, 2000). In the fluffy sculpin Oligocottus snyderi, a resident of lower tide pools during low tide, significant increases in liver HSP70 protein levels are evident $2-4 \mathrm{~h}$ after the beginning of the low tide event (Nakano and Iwama, 2002). Pulse-chase studies using $\left[{ }^{35} \mathrm{~S}\right]$ methionine incorporation into Morris hepatoma 7777 cells following heat conditioned at $43^{\circ} \mathrm{C}$ for $0.5 \mathrm{~h}$ shows increasing protein synthesis peaking after $2 \mathrm{~h}$ with the response complete after 6-8 h (Landry et al., 1982). While the small sample sizes in this study precludes a rigorous analysis of the relationship between protein expression and thermal history, future field studies should consider this link.

\subsection{Climate change and range expansion}

Many marine taxa, including Kellet's whelk and other species along the North American west coast, are exhibiting poleward range expansion associated with climate change (Poloczanska et al., 2013). Kellet's whelk's range expansion, first documented in the 1980s, extends north of Point Conception along the central California coast to Monterey Bay (thus our cold-water study site at San Miguel Island is located near the edge of the species' historic range; Herrlinger, 1981). In addition to being driven by the longer-time scale warming of the ocean, the range expansions appear in part to be facilitated by anomalous northward- flowing ocean currents during El Niño Southern Oscillation (ENSO) events, which advect and disperse pelagic larvae to previously unoccupied northern regions (Chavez et al., 2002; Frischknecht et al., 2015; Lluch-Belda et al., 2003; Lynn and Bograd, 2002; Zacherl et al., 2003). Following recruitment, and particularly during the return to negative neutral ENSO years (i.e., non-ENSO years), these larval settlers and their later stages are exposed to cooler environmental conditions in the new poleward habitats. For example, the mean temperature $\left(9-14^{\circ} \mathrm{C}\right)$ in Kellet's whelk's expanded range along the central California coast is cooler than the mean temperature $\left(12-17^{\circ} \mathrm{C}\right)$ in the species' historic range in southern California (Zacherl et al., 2003). These shorter-term climate oscillations (e.g., ENSO events) that drive poleward range expansions, and hence the exposure of individuals in the expanded range to cold-stress, are expected to increase in frequency and intensity with climate change (Cai et al., 2015; Power et al., 2013; Yeh et al., 2009).

Analysis of whelks at San Miguel Island, which exhibits a mean temperature ( $\quad{ }^{\circ} \mathrm{C}$ ), which is within the temperature range $\left(9-14^{\circ} \mathrm{C}\right.$ ) found in the expanded geographic range, may provide clues about physiological responses whelks in the expanded geographic range may exhibit due to cold-stress. We found whelks from San Miguel to exhibit increased abundance of energy metabolism and oxidative stress proteins, suggesting oxidative damage of lipid membranes that is ameliorated by antioxidants and may aid in cold compensation. Similarly, abundances of cell signaling proteins were higher in whelks at San Miguel compared to whelks at Anacapa, indicating an importance for cell signaling regulation in colder environments. These results suggest that whelks may exhibit physiological changes in their proteome in order to cope with stress from colder environments. Such acclimation may also occur in Kellet's whelk's expanded range populations, and thus contribute to whelk survival and viability of the populations there (Simmonds et al., 2014; Zahn et al., 2016). However, testing these hypotheses will require proteomic analysis of whelks sampled from the species' expanded range, and quantification of demographic responses to the observed proteomic changes. In the meantime, this study provides an initial assessment of thermal stress costs that may be associated with marine species range shifts in response to climate change.

\subsection{Non-significant proteins and study limitations}

Proteomic analysis benefits from a well-described genomic/transcriptomic database from which peptide matches are acquired. For nonmodel organisms, like Kellet's whelk, very little peptide sequence information is available, thus limiting protein identification and experimental interpretation (Dowd, 2012; Tomanek, 2011). As our study is the first to analyze the proteome of the Kellet's whelk, we identified an additional 48 proteins that did not have significant differences in 
protein abundance due to island site using tandem mass spectrometry (Fig. S4; Table S1). Over half of the proteins identified were related to the cytoskeleton (Fig. S4; Table S1). Of the remaining proteins, we identified antioxidants (peroxiredoxin, glutathione peroxidase), molecular chaperones (protein disulfide isomerase, HSP70, HSP60), proteins related to protein degradation (proteasome subunit $\alpha$ ), and proteins involved in protein metabolism (glutamate dehydrogenase) (Fig. S4; Table S1). Supporting the validity of these protein identifications is the finding that many of the identified peptide sequences aligned with database information for the marine sea hare Aplysia californica. Our data reveal that Kellet's whelks have the cellular machinery capable of withstanding environmental change. Moreover, the non-significant changes in abundance of traditional cellular stress response proteins (HSPs, proteolysis, antioxidants) suggest that the proteomic differences between island populations are small. They also highlight that changes in protein functional categories (e.g., antioxidants) are specific to one of many antioxidant pathways (i.e., increase in the synthesis of the nonenzymatic antioxidant glutathione; Tomanek, 2015). In the case of some metabolic enzymes (e.g., mMDH, NADP-IDH and PDH) one isoform was significantly different while another isoform was not, highlighting the possible importance of different orthologous and paralogous homologs but also their PTMs in ecological physiology (Somero et al., 2017).

We expected our principal component analysis to show separation of island sites along PC1 with the warmest (Anacapa) and coldest (San Miguel) island sites located at opposite ends of the x-axis; however, this was not the case, as these two islands were actually located adjacent to each other (Fig. 4). This suggests a similarity in protein abundance changes in whelks from these two island sites. It may be possible that the thermal environments found at San Miguel and Anacapa are not sufficiently different from each other to influence the distribution of protein abundance variation contributing to separation of islands depicted by our PCA. Mean temperature 1 day prior to collection at Anacapa and San Miguel differ on average by $5.7^{\circ} \mathrm{C}$ and the thermal environment measured at each island is in the range experienced by whelks within their historic range (Zacherl et al., 2003). While our study only correlates thermal environments with proteomic profiles in Kellet's whelks, it is the first step towards identifying protein indicators that are of adaptive importance across thermal environments.

\section{Conclusion}

Using a naturally occurring thermal gradient occurring at the Northern California Channel Islands, our study is the first to analyze proteomic responses of the sub-tidal marine gastropod and fisheries species Kellet's whelk to temperatures experienced within the species' historic range. Our preliminary analyses identified changes in cytoskeletal proteins that may be indicative of both cold- (San Miguel) and warm-induced (Anacapa) stability effects remediated by increased protein abundance of myosin, actin and tubulin. Many of the metabolism proteins identified function in regulating ATP synthesis and we identified a trend of higher protein abundance in whelks from the cooler and intermediate island sites compared to whelks from Anacapa Island, possibly indicating metabolic compensation to changing thermal environments. We found initial evidence for remediation of oxidative damage to lipid membranes in whelks from both the cool (San Miguel) and warm (Anacapa) island sites. Cell signaling protein abundance was greater in whelks from all but Anacapa Island, possibly indicating a greater degree of cell signaling regulation in cooler environments. Our study provide many hypotheses regarding proteomic changes in whelks experiencing variable thermal environments that require further investigation that may provide insight into the physiological cost of thermal exposure in marine animals. What remains to be known is whether these cellular costs are reflected in a change of phenotype that could influence growth, reproduction, and/or survival of marine animals.

\section{Data accessibility}

Peptide sequence alignments were searched against protein BLAST in NCBI and accession numbers are provided in Table S1. Protein normalized spot volumes per animal replicate and island site are available upon request. Mass spectral evidence for each identified protein are available upon request from the authors.

\section{Author contributions}

M.C.V., C.W. and L.T. designed the experiment and analysis. The study was conducted by M.C.V., M.L. and C.W. M.C.V and R.W. analyzed the data and M.C.V., M.L., R.W., C.W. and L.T. wrote the manuscript. All authors approved the final manuscript.

\section{Declaration of interests}

Declaration of interests: none.

\section{Acknowledgements}

We thank Sawyer Randal for laboratory assistance. This research was supported by grants to C.W. from the California Polytechnic State University Research, Scholarly, and Creative Activities program (grant \#2015-16-31) and California State University Council on Ocean Affairs, Science and Technology program (grant \#COAST-RR-2014-001), and research scholarships to M.L. from the California Polytechnic State University Frost program and STEM Teacher and Researcher program. We thank C. Gotschalk and L. Washburn for providing the temperature data. Support for the temperature measurements was provided by the Channel Islands National Marine Sanctuary and the SBC-LTER. Support is in the form of in-kind services such as instrument setup, data management, boat time, and diver time. PISCO provided funding for the temperature measurements earlier during the 2000's. During writing of the manuscript, M.C.V. was supported by funding from the National Science Foundation (PRFB DBI-1401357). Additional funding was provided by a National Science Foundation grant (grant \#IOS-071708) to L.T.

\section{Appendix A. Supplementary data}

Supplementary data to this article can be found online at https:// doi.org/10.1016/j.marenvres.2019.06.002.

\section{References}

Abele, D., Puntarulo, S., 2004. Formation of reactive species and induction of antioxidant defence systems in polar and temperate marine invertebrates and fish. Comp. Biochem. Physiol. A 138, 405-415.

Aseltine-Neilson, D., Brady, B., Connel, M., Kalvass, P., Laughlin, L., Leos, B., Mello, J., Neillands, G., Roberts, E., Taniguchi, I., Vejar, A., Watanabe, R., 2006. Review of some California fisheris for 2005: Coastal pelagic finfish, market squid, dungeness crab, sea urchin, abalone, kellet's whelk, groundfish, highly migratory species, ocean salmon, nearshore live-fish, pacific herring, and white seabass. In: Venrick, E., Hewitt, R., Rogers-Bennett, L. (Eds.), California Cooperative Oceanic Fisheries Investigations Reports. Scripps Institution of Oceanography, La Jolla, California, pp. 9-29.

Benjamini, Y., Hochberg, Y., 1995. Controlling the false discovery rate: a practical and powerful approach to multiple testing. J. R. Stat. Soc. B. Met. 57, 289-300.

Berg, J.S., Cheney, R.E., 2002. Myosin-X is an unconventional myosin that undergoes intrafilopodial motility. Nat. Cell Biol. 4, 246-250.

Berg, J.S., Derfler, B.H., Pennisi, C.M., Corey, D.P., Cheney, R.E., 2000. Myosin-X, a novel myosin with plechstrin homology domains, associates with regions of dynamic actin. J. Cell Sci. 113, 3439-3451.

Berth, M., Moser, F.M., Kolbe, M., Bernhardt, J., 2007. The state of the art in the analysis of two-dimensional gel electrophoresis images. Appl. Microbiol. Biotechnol. 76, 1223-1243.

Cai, W.J., Wang, G.J., Santoso, A., McPhaden, M.J., Wu, L.X., Jin, F.F., Timmermann, A., Collins, M., Vecchi, G., Lengaigne, M., England, M.H., Dommenget, D., Takahashi, K., Guilyardi, E., 2015. Increased frequency of extreme La Nina events under greenhouse warming. Nat. Clim. Change 5, 132-137. 
Chandel, N.S., 2015. Navigating Metabolism. Cold Spring Harbor Laboratory Press, Cold Spring Harbor, New York.

Chavez, F.P., Pennington, J.T., Castro, C.G., Ryan, J.P., Michisaki, R.P., Schlining, B., Walz, P., Buck, K.R., McFadyen, A., Collins, C.A., 2002. Biological and chemical consequences of the 1997-1998 El Nino in central California waters. Prog. Oceanogr. 54, 205-232.

Dilly, G.F., Young, C.R., Lane, W.S., Pangilinan, J., Girguis, P.R., 2012. Exploring the limit of metazoan thermal tolerance via comparative proteomics: thermally induced changes in protein abundance by two hydrothermal vent polychaetes. P. Roy. Soc. BBiol. Sci. 279, 3347-3356.

Diz, A.P., Carvajal-Rodriguez, A., Skibinski, D.O., 2011. Multiple hypothesis testing in proteomics: a strategy for experimental work. Mol. Cell. Proteom. 10 M110 004374.

Dowd, W.W., 2012. Challenges for biological interpretation of environmental proteomics data in non-model organisms. Integr. Comp. Biol. 52, 705-720.

Ellington, W.R., 2001. Evolution and physiological roles of phosphagen systems. Annu. Rev. Physiol. 63, 289-325.

Feder, M.E., Hofmann, G.E., 1999. Heat-shock proteins, molecular chaperones, and the stress response: evolutionary and ecological physiology. Annu. Rev. Physiol. 61, 243-282.

Federhen, S., 2012. The NCBI Taxonomy database. Nucleic Acids Res. 40, D136-D143.

Fields, P.A., Zuzow, M.J., Tomanek, L., 2012. Proteomic responses of blue mussel (Mytilus) congeners to temperature acclimation. J. Exp. Biol. 215, 1106-1116.

Frischknecht, M., Munnich, M., Gruber, N., 2015. Remote versus local influence of ENSO on the California current system. J. Geophys. Res.-Oceans 120, 1353-1374.

Grimsrud, P.A., Xie, H., Griffin, T.J., Bernlohr, D.A., 2008. Oxidative stress and covalent modification of protein with bioactive aldehydes. J. Biol. Chem. 283, 21837-21841.

Halpern, B.S., Cottenie, K., Broitman, B.R., 2006. Strong top-down control in southern California kelp forest ecosystems. Science 312, 1230-1232.

Hammond, J.W., Cai, D., Verhey, K.J., 2008. Tubulin modifications and their cellular functions. Curr. Opin. Cell Biol. 20, 71-76.

Hazel, J.R., 1995. Thermal adaptation in biological membranes: is homeoviscous adaptation the explanation? Annu. Rev. Physiol. 57, 19-42.

Herrlinger, T.J., 1981. Range extension of Kelletia kelletii. Veliger 24, 78.

Hochachka, P.W., Somero, G.N., 2002. Temperature. In: Hochachka, P.W., Somero, G.N. (Eds.), Biochemical Adaptations: Mechanism and Process in Physiological Evolution. Oxford University Press, New York, New York, pp. 290-449.

Kushner, D.T., Rassweiler, A., McLaughlin, J.P., Lafferty, K.D., 2013. A multi-decade time series of kelp forest community structure at the California Channel Islands: "Ecological Archives" E094-245. Ecology 94, 2655.

Landry, J., Bernier, D., Chretien, P., Nicole, L.M., Tanguay, R.M., Marceau, N., 1982. Synthesis and degradation of heat shock proteins during development and decay of thermotolerance. Cancer Res. 42, 2457-2461.

Lluch-Belda, D., Lluch-Cota, D.B., Lluch-Cota, S.E., 2003. Scales of interannual variability in the California current system: associated physical mechanisms and likely ecological impacts. Cal. Coop. Ocean. Fish. 44, 76-85.

Ludeña, R.F., 1997. Multiple forms of tubulin: different gene products and covalent modifications. In: International Review of Cytology. Academic Press, pp. 207-275.

Lynn, R.J., Bograd, S.J., 2002. Dynamic evolution of the 1997-1999 El Niño-La niña cycle in the southern California current system. Prog. Oceanogr. 54, 59-75.

Mounier, N., Arrigo, A.-P., 2002. Actin cytoskeleton and small heat shock proteins: how do they interact? Cell Stress Chaperones 7, 167-176.

MUR MEaSUREs Project, J.P.L., 2015. GHRSST Level 4 MUR Global Foundation Sea Surface Temperature Analysis (v4.1). Ver. 4.1. PO, DAAC, CA, USA. https://doi.org/ 10.5067/GHGMR-4FJ04, Accessed date: 10 June 2017.

Nakano, K., Iwama, G.K., 2002. The 70-kDa heat shock protein response in two intertidal scupins Oligocottus maculosus and O. snyderi: relationship of hsp70 and thermal tolerance. Comp. Biochem. Physiol. A 133, 79-94.

Pascovici, D., Handler, D.C., Wu, J.X., Haynes, P.A., 2016. Multiple testing corrections in quantitative proteomics: a useful but blunt tool. Proteomics 16, 2448-2453.

Poloczanska, E.S., Brown, C.J., Sydeman, W.J., Kiessling, W., Schoeman, D.S., Moore, P.J., Brander, K., Bruno, J.F., Buckley, L.B., Burrows, M.T., Duarte, C.M., Halpern, B.S., Holding, J., Kappel, C.V., O'Connor, M.I., Pandolfi, J.M., Parmesan, C., Schwing, F., Thompson, S.A., Richardson, A.J., 2013. Global imprint of climate change on marine life. Nat. Clim. Change 3, 919-925.

Pörtner, H.O., Van Dijk, P.L.M., Hardewig, I., Sommer, A., 2000. Levels of metabolic cold adaptation: tradeoffs in eurythermal and stenothermal ectotherms. In: Davison, W. Howared-Williams, C., Broady, P. (Eds.), Antarctic Ecosystems: Models for Wider Ecological Understanding. Caxton Press, Christchurch New Zealand, pp. 109-122.

Pörtner, H.O., Bennett, A.F., Bozinovic, F., Clarke, A., Lardies, M.A., Lucassen, M., Pelster, B., Schiemer, F., Stillman, J.H., 2006. Trade-offs in thermal adaptation: the need for a molecular to ecological integration. Physiol. Biochem. Zool. 79, 295-313.

Power, S., Delage, F., Chung, C., Kociuba, G., Keay, K., 2013. Robust twenty-first-century projections of El Niño and related precipitation variability. Nature 502, 541-545.
Romero, M.R., Walker, K.M., Cortez, C.J., Sanchez, Y., Nelson, K.J., Ortega, D.C., Smick, S.L., Hoese, W.J., Zacherl, D.C., 2012. Larval diel vertical migration of the marine gastropod Kelletia kelletii (Forbes, 1850). J. Mar. Biol. 1-9 2012.

Rosenthal, R.J., 1970. Observations on the reproductive biology of the Kellet's whelk, Kelletia kelletii. Veliger 12, 319-324.

Rosenthal, R.J., 1971. Trophic interaction between the sea star Pisaster giganieus and the gastropod Kelletia kelletii. Fish. Bull. Natl. Oc. At. 69, 669-679.

Roskoski Jr., R., 2012. ERK1/2 MAP kinases: structure, function, and regulation. Pharmacol. Res. 66, 105-143.

Simmonds, S.E., Kinlan, B.P., White, C., Paradis, G.L., Warner, R.R., Zacherl, D.C., 2014. Geospatial statistics strengthen the ability of natural geochemical tags to estimate range-wide population connectivity in marine species. Mar. Ecol. Prog. Ser. 508, 33-51.

Sokolova, I.M., 2003. Metabolic plasticity and critical temperatures for aerobic scope in a eurythermal marine invertebrate (Littorina saxatilis, Gastropoda: littorinidae) from different latitudes. J. Exp. Biol. 206, 195-207.

Sokolova, I.M., 2013. Energy-limited tolerance to stress as a conceptual framework to integrate the effects of multiple stressors. Integr. Comp. Biol. 53, 597-608.

Sokolova, I.M., Frederich, M., Bagwe, R., Lannig, G., Sukhotin, A.A., 2012. Energy homeostasis as an integrative tool for assessing limits of environmental stress tolerance in aquatic invertebrates. Mar. Environ. Res. 79, 1-15.

Somero, G.N., 2010. The physiology of climate change: how potentials for acclimatization and genetic adaptation will determine 'winners' and 'losers. J. Exp. Biol. 213, 912-920.

Somero, G.N., Lockwood, B.L., Tomanek, L., 2017. Biochemical Adaptations: Responses to Environmental Challenges from Life's Origins to the Anthropocene. Sinauer Associates, Sunderland, MA.

Sonna, L.A., Fujita, J., Gaffin, S.L., Lilly, C.M., 2002. Molecular biology of thermoregulation invited review: effects of heat and cold stress on mammalian gene expression. J. Appl. Physiol. 92, 1725-1742.

St-Pierre, J., Charest, P.-M., Guderley, H., 1998. Relative contribution of quantitative and qualitative changes in mitochondria to metabolic compensation during seasonal acclimatisation of rainbow trout Onchorynchus mykiss. J. Exp. Biol. 201, 2961-2970.

Storey, J.D., Tibshirani, R., 2003. Statistical significance for genomewide studies. P. Natl. Acad. Sci. USA 100, 9440-9445.

Terman, J.R., Kashina, A., 2013. Post-translational modification and regulation of actin. Curr. Opin. Cell Biol. 25, 30-38.

Thieringer, H.A., Jones, P.G., Inouye, M., 1998. Cold shock and adaptation. Bioessays 20 49-57.

Tomanek, L., 2011. Environmental proteomics: changes in the proteome of marine organisms in response to environmental stress, pollutants, infection, symbiosis, and development. Annu. Rev. Mar. Sci. 3, 373-399.

Tomanek, L., 2014. Proteomics to study adaptations in marine organisms to environmental stress. J. Proteomics 105, 92-106.

Tomanek, L., 2015. Proteomic responses to environmentally induced oxidative stress. J. Exp. Biol. 218, 1867-1879.

Tomanek, L., Somero, G.N., 2000. Time course and magnitude of synthesis of heat-shock proteins in congeneric marine snails (Genus tegula) from different tidal heights. Physiol. Biochem. Zool. 73, 249-256.

Tomanek, L., Zuzow, M.J., 2010. The proteomic response of the mussel congeners Mytilus galloprovincialis and $M$. trossulus to acute heat stress: implications for thermal tolerance limits and metabolic costs of thermal stress. J. Exp. Biol. 213, 3559-3574.

Vasquez, M.C., Beam, M., Blackwell, S., Zuzow, M.J., Tomanek, L., 2017. Sirtuins regulate proteomic responses near thermal tolerance limits in the blue mussels Mytilus galloprovincialis and Mytilus trossulus. J. Exp. Biol. 220, 4515-4534.

Verhey, K.J., Gaertig, J., 2007. The tubulin code. Cell Cycle 6, 2152-2160.

Vetter, I.R., Wittinghofer, A., 2001. The guanine nucleotide-binding switch in three dimensions. Science 294, 1299-1304.

Wallin, M., Strömberg, E., 1995. Cold-stable and cold-adapted microtubules. Int. Rev. Cytol. 157, 1-31.

Weeds, A., Maciver, S., 1993. F-actin capping proteins. Curr. Opin. Cell Biol. 5, 63-69.

White, C., Selkoe, K.A., Watson, J., Siegel, D.A., Zacherl, D.C., Toonen, R.J., 2010. Ocean currents help explain population genetic structure. P. Roy. Soc. B-Biol. Sci. 277 1685-1694.

Yeh, S.W., Kug, J.S., Dewitte, B., Kwon, M.H., Kirtman, B.P., Jin, F.F., 2009. El Niño in a changing climate. Nature 461, 511-514.

Zacherl, D.C., Gaines, S.D., Lonhart, S.I., 2003. The limits to biogeographical distributions: insights from the northward range extension of the marine snail, Kelletia kelletii (Forbes, 1852). J. Biogeogr. 30, 913-924.

Zahn, L.A., Claisse, J.T., Williams, J.P., Williams, C.M., Pondella, D.J., 2016. The biogeography and community structure of kelp forest macroinvertebrates. Mar. Ecol. 37 $770-785$. 